JOURNAL OF SECURITY AND SUSTAINABILITY ISSUES

ISSN 2029-7017 print/ISSN 2029-7025 online

2021 Volume 11

https://doi.org/10.47459/jssi.2021.11.24

\title{
SUICIDE ATTEMPTS AND SUICIDES IN THE VIEWS OF PEOPLE SUBJECT TO IMPRISONMENT
}

\author{
Slawomir Cudak \\ Academy of Justice, 50 Wiśniowa Street, 02-520 Warsaw, Poland \\ E-mail: slawomir.cudak@swws.edu.pl
}

Received 23 October, 2020; accepted 14 April 2021; published 30 June 2021

\begin{abstract}
Suicide attempts and suicides occur in every social group. The intensification of suicidal phenomena is manifested in the group of people subject to imprisonment. The main categories of suicidal causes fall into the area of mental, social and biological determinants. The most common cause, according to research on the people in prison, is the deprivation of personal freedom of an individual and life problems disrupting the functioning of the family. People subject to imprisonment express various attitudes towards suicide attempts and suicides. Almost every fourth inmate shows a positive attitude towards suicidal behaviour. This group of inmates should be provided with special educational and rehabilitation care.
\end{abstract}

Keywords: Suicide attempts; suicides; suicidal behaviour; security; causes of suicide

Reference to this paper should be made as follows: Cudak, S. 2021. A suicide attempts and suicides in the views of people subject to imprisonment. Journal of Security and Sustainability Issues, 11, 277-285. https://doi.org/10.47459/jssi.2021.11.24

JEL Classifications: I10

Additional disciplines: imprisonment, freedom

\section{Introduction}

The biological life of every human being ends in death. It is a natural component of life that closes the functioning of a dying person, often difficult to accept by relatives. The end of human life as a result of suicide is not a natural phenomenon. It is a consequence of multifactorial life conditions, not necessarily in the area of social pathologies.

The concept of suicide is not new in the literature. Already Emil Durkheim defined the concept of suicide as "cases of death resulting directly or indirectly from a positive or negative act of the victim himself, which he knows will produce this result" (E. Durkheim, 1997, p. 97).

A similar definition of suicide was presented by the World Health Organization, however, paying attention to broader elements related to a suicide attempt. It describes suicide as "act with a fatal outcome which the deceased, knowing or expecting a fatal outcome, had initiated and carried out with the purpose of provoking the changes he desired" (S. Kawula, 2006, p. 590). The definition of suicide presented by the World Health Organization clearly indicates that:

- suicide always ends in a fatal act,

- a person, when attempting suicide, does so consciously,

- suicide is an action planned by a person, 
- suicide is undertaken independently without the actions of other people.

In suicidology, in addition to the suicide act, we also find a negative phenomenon in the form of a suicide attempt. Brunon Hołyst (2012, p. 89) defines a suicide attempt as "a deliberate, voluntary act that a person undertook to hurt himself not being completely sure if he would survive, but the resulting injuries do not end in death".

Suicide attempts are a manifestation of negative behaviours, where, on the one hand, traumatic and often critical life situations limit the proper functioning of a human being, and on the other hand constitute emotional and social opposition in the form of an internal "crisis" that is tragic in psychological circumstances.

Suicide attempts are, to a greater extent than threats of suicide, behaviours which, in their suicidal process, directly or indirectly lead to negative consequences of committing suicide. In addition, suicide threats are usually a verbal behaviour, while suicide attempts are expressed in the form of actions that may lead to self-harm to the human body. Suicidal behaviour in the form of suicide attempts is often aimed at provoking in the immediate social environment (family, prison, peer group) some reflections and changes in behaviour, living conditions, emotional and social relationship of the human environment to the person attempting suicide.

Among the many factors that cause the possibility of committing suicide attempts, M. Wójcik (2006, p. 20) lists, among others:

- personal characteristics of the individual person, such as: withdrawal, aggression, low level of emotional and social development, a sense of indifference and hopeless life situations,

- traumatic family environment in the form of conflict, domestic violence, aggressive behaviour, death of a parent, divorce of parents, mental illness of a family member,

- previous behaviour manifested in attempted suicide,

- mental and physical disorders and diseases,

- direct contact with a person with suicidal behaviour.

The distinguished elements disrupting the social and emotional functioning of human life, mentioned by M. Wójcik, are important in the suicide attempts undertaken, but they do not contain certain components and negative events in the lives of adolescents and adults, including inmates. These include, among others: abandonment by the family, heartbreaks, aggression and violence in the work environment, difficulties at school, loss of the family as a result of divorce.

Literature on suicide presents various motives and mechanisms of the emergence of suicidal tendencies. An interesting classification of various types of suicidal behaviour was presented by R. Radziwiłowicz and W. Radziwiłowicz (1998 p. 48). They list:

- balance suicides - behaviours and suicidal actions undertaken by choice, committed by people in a difficult life situation, often without the possibility of eliminating such physical or mental suffering,

- psychotic suicides - they occur in mental illnesses, especially in deep depression or schizophrenia,

- stimulating suicides - manifested in personality disorders causing self-harm,

- reactive suicides - they are a certain result of a reaction to the loss of a loved one or other loss, e.g. of work, property, position,

- discharging suicides - these are specific reactions of people, especially at a young age, to difficult situations,

- manipulative suicides - they result from certain acquired and learned behaviours aimed at achieving the desired goal by influencing the social environment.

Motivations that trigger suicidal behaviour in the form of suicide attempts and suicides should be understood in the multifactorial context of social, biological, emotional and economic life of a human being. Brunon Hołyst (2014, p. 171), analysing the motivation of suicidal behaviour, especially suicide acts, highlighted the following criteria in his division: psychological, philosophical, social and political-legal.

M. Kuć (2010, p. 57) lists the following important reasons for suicidal behaviour resulting from the mental functions of human beings: 
- emotional, subjective guilt that causes the need to punish oneself,

- mental and physical loneliness of a person,

- high level of anxiety,

- addiction, mainly to alcohol and drugs,

- hopelessness and loss of the meaning of life,

- mental disorders,

- loss of a loved one,

- strong psychological trauma,

- long-lasting and strong stress,

- helplessness in the face of problems in family life,

- unmet mental, social and financial needs.

Among the various negative determinants of psychological victimological causes, depression is the strongest factor motivating to attempt or commit suicide. Traumatic suicidal behaviour resulting from this mental illness causes a state of loneliness, hopelessness, indifference, and the lack of meaning in life, which motivate an individual to attempt or commit suicide.

However, many suicide attempts and suicides are not a consequence of depression and typical mental disorders. Apart from psychological factors, social conditions are also important in undertaking suicide attempts and acts of killing oneself.

Modern life in a variety of social settings (school, family, prison, peer environment, local and professional environments) is under threat. It brings many stress-generating situations, the disappearance and impairment of ties between people and human groups is visible. We observe an increase in rivalry, competition and internal aspirations of individuals. There is also an increase in conflict, aggression and even emotional and psychological violence in communities between social groups and between individuals. Disruption of these environmental conditions causes the state of loneliness and emotional and social loneliness of children, adolescents and the adult part of society (S. Cudak 2014, p. 76).

The problem of loneliness of individuals in recent decades has become an increasingly common phenomenon. Manifestations of a deep state of loneliness may lead to suicide attempts and even committing suicide.

Małgorzata Kuć (2010) lists the following causes of environmental determinants of suicides:

- living in a metropolitan environment,

- symptoms of economic crises,

- unemployment,

- conflicts in the family environment.

A broader classification of a variety of social drivers of suicidal behaviour is provided by B. Hołyst (2000). In his division, he lists the following groups and elements of environment-related causes of suicide attempts and suicides:

1. Socio-demographic features,

- gender,

- age - the period of adolescence entails the biggest risk,

- education - a low level of education means being more susceptible to suicide attempts.

\section{Low economic status.}

3. Disturbed relationships with people from the closest social environment,

- disturbed dialogue in the family environment,

- elimination of the emotional bond in the family, 
- failure to meet emotional and social needs with loved ones.

4. Pathological behaviour of an individual and his/her immediate social environment,

- family broken up through divorce,

- alcoholism in the family,

- verbal and physical aggression,

- suicide attempts in the family of origin,

- emotional threats (attitudes of avoidance, rejection, addiction, violence).

In the area of biological determinants, as Brunon Hołyst (2012) rightly proves, deficiencies or disruptions of certain chemical substances that function in the cerebral cortex are quite important in suicide attempts and suicides. They disrupt neurophysiological processes, including threats to the physical activity of a human being. Moreover, suicidal behaviour may be manifested through genetic factors of inheritance from past generations of the family of origin.

\section{Methodological notes}

Suicide attempts and suicides are usually a consequence of critical life situations of an individual. In recent decades, there has been an increase in suicidal behaviour in various social environments. The multitude of factors provoking a suicide act makes it difficult, from the forensic point of view, to limit or eliminate suicidal behaviour. Society in highly civilized countries, including Poland, expresses a negative view of suicide acts. In each case of suicide, the social environment indicates one or more disturbed conditions that cause suicidal behaviour.

In the procedure undertaken, the research objective was to learn about the views of the social group of inmates on the causes of suicidal behaviour and their attitude towards suicide attempts and suicides.

An important element of the conducted research is the formulation of research problems. The following problems were highlighted in the test procedure:

1. What are the most important causes of suicide attempts and suicides in the views of people in a correctional facility?

2. Whether and to what extent deprivation of personal freedom triggers the motivation to attempt or commit suicide?

3. What is the attitude of the respondents subject to imprisonment from the rural and urban environment to attempting and committing suicide?

The following hypotheses were formulated in the course of the research:

1. Inmates in a correctional facility, among various reasons, recognise the isolation of a human being in prison as the most important reason for attempting and committing suicide.

2. If inmates come from an urban environment, there is a greater tolerance and even a positive attitude towards suicide attempts and suicides than in inmates from a rural environment.

The research was carried out using the diagnostic survey method. In the area of this method, the survey and interview technique were used. The survey was fully anonymous in order to obtain more reliable answers. It was built on the respondent's record and eight questions examining the causes of suicide attempts and suicides and their attitude to suicidal behaviour.

The survey was conducted in the entire research group (96 people), while the interview was conducted with a 
randomly selected group of 16 inmates.

The research procedure was performed in the Piotrków Trybunalski Remand Centre in the second half of 2020. In the course of the research, 126 inmates were randomly selected. Out of this group, 96 people agreed to conduct research activities.

\section{Analysis of research results}

Suicide attempts and actions that lead to taking one's own life always evoke emotions among the close and distant people. Often, family, friends, local community and fellow inmates ask themselves about the cause, reason and circumstances of suicidal acts by accompanying human beings in social environments.

Motivations triggering suicidal behaviour in the form of suicide attempts or suicides may be manifested in homogeneous factors that are deeply and emotionally embedded in the psyche of an individual threatening his/her social functioning, they can also appear in complex mental, social and biological elements, creating a negative component of the suicidal personality.

Suicide attempts and acts of suicide are most often a demonstration, opposition to the existing critical life condition. There are individuals that express inner hopelessness, indifference, difficulty, suffering, aggression that lead to suicidal behaviour, manifesting not only suicide threats but also suicide attempts and suicide.

In the research procedure carried out in the prison, an attempt was made to find out the views of inmates on the reasons for committing suicide. The opinions expressed on the causes of suicide attempts and suicides by inmates are presented in Table 1.

Table 1. The causes of suicide attempts and suicides in the opinion of the surveyed inmates $(\mathrm{N}=96)$

\begin{tabular}{|c|l|c|c|}
\hline No. & Causes of suicidal behaviour (suicide attempts and suicides) & N & $\%$ \\
\hline 1 & Family issues & 29 & 30.2 \\
\hline 2 & Financial difficulties & 27 & 28.1 \\
\hline 3 & Heartbreak & 28 & 29.2 \\
\hline 4 & School difficulties & 16 & 16.7 \\
\hline 5 & Mental disorder & 29 & 30.2 \\
\hline 6 & Prison isolation & 31 & 32.3 \\
\hline 7 & Work problems & 12 & 12.5 \\
\hline 8 & Other & 16 & 16.7 \\
\hline & Total & 188 & $195.8^{*}$ \\
\hline
\end{tabular}

* The answers in total give more than $100 \%$ because the respondents (inmates) gave one or more reasons for suicide attempts.

Prison isolation is the greatest cause of suicide attempts and acts of suicide in the views of inmates in penitentiary institutions. Almost every third respondent in a prison (32.3\%) expresses the opinion that imprisonment is a significant reason to manifest suicide attempts or even attacks on one's life. Similar research results were obtained by M. Kuć (2013) who stated that rapid changes in the actual and legal situation of an individual and the lack of adaptation processes, especially in the initial period of imprisonment, cause suicidal behaviour among inmates.

The statements of the imprisoned respondents confirm their opinions on suicide attempts and acts, "a prison sentence is a significant isolation from society for an individual, therefore people cannot cope with this problem and reach for the last resort in the form of suicide attempts". Other characteristic statements: "restriction of freedom is a great psychological burden for the individual, often inmates are unable to cope with the new, humiliating prison conditions, and therefore may commit suicide". "The penalty of imprisonment is a great difficulty in overcoming the conditions of functioning. These difficulties are created by the prison service and 
fellow inmates, hence the suicide attempts in the prison".

A large proportion of respondents (30.2\%) detained in prison expresses the view that problems in the form of conflicts and various critical situations in the family may be the reason for suicidal behaviour in the form of suicide attempts and suicides. This type of causes is characterised in the following opinions of the surveyed inmates. "Constant family conflicts may cause suicide attempts". "Aggression and violence of parents towards a child may make him/her want to commit suicide". "When a child is in difficult life situation and is deprived of parental support, he/she may attempt a suicide".

In the category of causes of suicide inherent in the family environment, people subject to imprisonment mentioned such features as:

- family conflicts with high emotional load,

- constant verbal aggression causing stress in a family member,

- various forms of domestic violence,

- parental attitudes that reject the child,

- disappearance of emotional and social ties in the family,

- lack of help, kindness towards the child in the family environment,

- the loneliness of the child in his/her own family.

A similar number (29) of imprisoned respondents constituting $30.2 \%$ of all respondents expressed the view that various types of mental diseases are the main cause of suicide attempts and suicides. Qualitative research confirms this type of motivation for attempting a suicide. "Depression may be the leading cause of suicide". "Mental disorders can often cause a person to commit suicide". "The use of psychoactive substances most often causes a disorder in the human psyche and may be the cause of suicide attempts".

In the views of the surveyed inmates, 28 respondents (29.2\%) stated that a heartbreak may be a significant cause of taking negative, affective actions in the form of suicide attempts. The surveyed inmates define this category of suicidal causes as follows: "betrayal of a fiancée may lead to a psychological distress". "Betrayal of a partner sometimes causes serious difficulties in life, which may lead to a suicide attempt". "Being abandoned by a loved one causes a critical life situation that may result in a suicide attempt".

Financial difficulties constitute the next group of suicidal causes. This type of reasons for suicide attempts is mentioned by $28.1 \%$ of the surveyed inmates. Economic poverty in the views of inmates is:

- critical life situations,

- no prospects for further life,

- lack of material resources for biological life,

- elimination of the meaning of life,

- constant stress due to shortage of money,

- mental breakdown related to the loss of material goods.

In the opinion of the respondents in prison, the next cause of suicide attempts and suicides is the school difficulties of children and adolescents. From among the surveyed inmates, $16.7 \%$ of respondents considered that school failures, mainly in secondary schools, may cause a tendency to attempt a suicide.

Qualitative research (statements of the surveyed inmates) draws attention to the following determinants of suicidal causes inherent in the school difficulties of children:

- educational difficulties at school,

- failures in the acquisition of knowledge,

- lack of promotion to the next grade,

- misunderstandings with teachers,

- constant conflicts with the class colleagues,

- the child's sense of loneliness among schoolmates. 
The smallest category of suicidal causes in the views of the surveyed inmates are work problems. Few of the respondents (12.5\%) indicated the risk of committing suicide as a result of various negative conditions that can be found in dysfunctional institutions and workplaces. The most frequently mentioned reasons of suicide attempts and suicides resulting from work problems indicated by inmates are:

- high expectations and emotional pressure towards employees,

- conflicts with the management of the facility,

- conflicts, misunderstandings and verbal aggression between colleagues,

- dismissals from work.

Other reasons, not included in research categories, were indicated by $16.7 \%$ of the surveyed inmates. They mentioned, among others, such negative conditions of human life as: alcoholism, drug overdose, loneliness, physical suffering due to illness.

The first hypothesis formulated in the methodological part concerning prison isolation as the most important cause of suicide attempts and suicides was fully confirmed in the opinions from respondents in the prison. Almost every third respondent (32.3\%) expressed the opinion that social isolation in the form of incarceration also causes a certain emotional disorder that triggers the motivation to attempt or even commit suicide.

In the research process, we were also interested in the issue of the inmates' attitude towards suicidal behaviour in the form of suicide attempts and suicides.

The views of the surveyed inmates regarding suicide attempts and suicides are presented in Table 2 .

Table 2. The ratio of views of the surveyed inmates from the rural and urban environment to suicidal behaviour in the form of suicide attempts and suicides.

\begin{tabular}{|c|c|c|c|c|c|c|c|}
\hline \multirow{2}{*}{ No. } & \multirow{2}{*}{$\begin{array}{c}\text { Living environment } \\
\text { Attitude to suicidal behaviour }\end{array}$} & \multicolumn{2}{|c|}{ Rural } & \multicolumn{2}{|c|}{ Urban } & \multicolumn{2}{|c|}{ Total } \\
\hline & & $\mathrm{N}$ & $\%$ & $\mathrm{~N}$ & $\%$ & $\mathrm{~N}$ & $\%$ \\
\hline 1 & Positive & 7 & 17.1 & 16 & 29.1 & 23 & 23.9 \\
\hline 2. & Negative & 23 & 56.1 & 22 & 40.0 & 45 & 46.9 \\
\hline 3. & Neutral & 11 & 26.8 & 17 & 30.9 & 28 & 29.2 \\
\hline 4. & Total & 41 & 100.0 & 55 & 100.0 & 96 & 100.0 \\
\hline
\end{tabular}

The analysis of the total research results presented in Table 2 proves that a positive attitude to the occurring suicide attempts and suicide is expressed by as many as $23.9 \%$ of respondents in prisons. Almost every fourth person expresses the view that the manifestations of suicide attacks constitute a certain state of despair, a critical random situation, a sense of danger to which a person wants to draw attention to the social environment through his/her suicidal behaviour.

Qualitative research confirms the positive attitude towards suicides and suicide attempts in this group of respondents. "A suicide act is a kind of courage", "a change in the behaviour of the social environment towards a person may occur due to a suicide attempt". "The act of suicide is a kind of heroism of an individual, by this desperate behaviour a person expresses disagreement with the existing conditions and reality".

Much more respondents from the urban environment (29.1\%) than from the rural environment (17.1\%) expressed a positive view on the suicide acts undertaken. These differences result from greater life degradation as well as social and emotional dysfunction of people in prison from the urban environment.

Less than half of the imprisoned respondents (46.9\%) have shown negative views on suicidal behaviour in the form of suicide attempts and suicides. This group of respondents critically assessed the negative behaviour of individuals who attempt to kill themselves. They state that: "people who attempt suicide are mentally weak". "I am a firm opponent of forcing changes in the behaviour of the prison workers by using suicide attempts". 
"Taking one's life, even in difficult life situations, is reprehensible". "People who think about suicide must be opposed and supported".

In the group of respondents expressing negative views on suicidal behaviour, there are significantly more inmates from rural environment $(56.1 \%)$. Only $40.0 \%$ of respondents from the urban environment have a negative attitude towards suicide attempts and suicides.

A fairly large proportion of the imprisoned respondents (29.2\%) expresses an indifferent attitude towards suicidal behaviour in the form of suicidal acts. In this group of respondents, slightly more people from the urban environment (30.9\%) are indifferent to suicidal acts than the respondents from the rural environment $(26.8 \%)$.

Summarizing the results of research in the area of opinions and views on suicide attempts and suicides of people in prison, it should be stated that a disturbingly high percentage of respondents expresses a positive attitude towards the studied suicide phenomenon.

The formulated second hypothesis that the background of the inmates' origin influences the emotional attitude to suicide attempts and suicides was also confirmed. Much more inmates from the urban environment express a positive attitude to suicidal behaviour in the form of suicide acts than respondents from the rural environment. Statistical significance of this difference is $\mathrm{x}^{2}=8.62, \mathrm{df}=6, \mathrm{Pi} \leq 0.05$. It proves that the environment differentiates the views on undertaken suicidal acts.

To a lesser extent, the negative opinion in the emotional and social sphere of inmates from the rural environment, expressed in suicide acts, results, among others, from:

- stronger interpersonal bond in a rural environment,

- greater social control in small local environments,

- critical and negative assessment of suicidal acts,

- the adopted value of human life in the dominant Christian faith.

\section{Conclusions}

Human life is the highest value there is. During his/her ontogenetic life, a person is a bio-socio-cultural unit. This means that in the area of our functioning, from the first stages of development to the stage of old age, biological, social and cultural conditions have a significant impact. The social environment of an individual is an essential element in the development and life. Disrupted functioning of the social environment, both immediate and more distant, usually causes a threat to the mental functions of children, adolescents and the adult part of society.

In recent decades, there has been an impoverishment and even elimination of social and emotional ties in the local, school and family environment. Conflicts, aggression, and violence in peer groups and families are observed more and more often. Difficulties in the educational and professional functioning of the adult part of society are also increasing. These elements of life threaten the co-existence with other people, often causing a state of loneliness of an individual in the family, local and professional environment. The state of loneliness, depression, imprisonment of a person at any age may lead to suicidal behaviour in the form of suicide attempts and suicides. There are many reasons for suicide acts. They can constitute homogeneous conditions that occur with great emotional and social strength. They can also appear in multifactorial and complex causes that disturb the functioning of individuals, their sense of identity and values, while at the same time making them take their own life. Study of these reasons may provide some pedagogical reflections for teachers and school educators as well as for psychologists and educators in prisons in order to undertake multilateral actions aimed at eliminating the motivating factors of suicidal behaviour. 


\section{References}

Carr A. (2004), Depresja i próby samobójcze młodzieży sposoby przeciwdziałania i reagowania [Depression and adolescent suicide attempts and ways of counteracting and responding], Gdańsk

Cudak S. (2014), Wybrane aspekty wewnątrzrodzinnych uwarunkowań osamotnienia dziecka [Selected aspects of intra-family determinants of a child's loneliness], Łódź

Hołys B. (2014), Bezpieczeństwo jednostki [Security of an individual], Warszawa

Hołys B. (2012), Suicydologia [Suicidology], Warszawa

Hołyst B. (2000), Wiktymologia [Victimology], Warszawa

Kawula S. (2006), Samobójstwo [Suicide], in: Encyklopedia pedagogiczna XXI w. [21st century pedagogical encyclopaedia] T V, ed, T. Pilch, Warszawa

Kuć M. (2010), Wiktymologia [Victimology], Warszawa

Radziwiłowicz R., Radziwiłowicz W. (1998), Samobójstwo i próby samobójcze - implikacje kliniczne i psychologiczne [Suicide and suicide attempts - clinical and psychological implications], "Psychologia Wychowania" Volume XL

Wójcik M. (2006), Samobójstwo wśród dzieci [Suicide among children], "Remedium” no. 2

Slawomir CUDAK a habilitated doctor, assistant professor at the Academy of Justice in Warsaw. He heads the Department of Resocialization Pedagogy. In 2008 he obtained a postdoctoral degree in humanities in the field of pedagogy at the Catholic University in Ružomberok. In 2005, he obtained a doctorate in humanities in the field of pedagogy at the Educational Research Institute in Warsaw. The scope of research interests is the family and its functioning in the modern, changing world. As part of scientific research, he diagnoses threats to the family, their causes and consequences.

ORCID ID: https://orcid.org/0000-0002-1485-7828

This work is licensed under the Creative Commons Attribution International License (CC BY). http://creativecommons.org/licenses/by/4.0/ 